\title{
FORMATION OF PARAMETERS OF FOAMED EXPLOSIVE MIXTURES FOR SEALING SOILS
}

\author{
Olena Han ${ }^{1}$, Viktor Boiko², Viktor Kravets 3 , Anatolii Han ${ }^{4}$ \\ ${ }^{1} 1$ Research laboratory for problems of seismic safety of technological explosions, Institute of Hydromechanics of the National Academy \\ of Sciences of Ukraine, Kyiv, Ukraine \\ Department of Geo-Engineering, National Technical University of Ukraine "Igor Sikorsky Kyiv Polytechnic Institute", Kyiv, Ukraine \\ gan elena@ukr.net \\ ORCID: http://orcid.org/0000-0003-0739-9600 \\ ${ }^{2}$ Research laboratory for problems of seismic safety of technological explosions, Institute of Hydromechanics of the National Academy of \\ Sciences of Ukraine, Kyiv, Ukraine \\ seismic-control@ukr.net \\ ORCID: http://orcid.org/0000-0003-3443-1688 \\ ${ }^{3}$ Department of Geo-Engineering, National Technical University of Ukraine "Igor Sikorsky Kyiv Polytechnic Institute", Kyiv, Ukraine \\ kravets@geobud.kiev.ua \\ ORCID: http://orcid.org/0000-0002-5231-0778 \\ ${ }^{4}$ Department of Geo-Engineering, National Technical University of Ukraine "Igor Sikorsky Kyiv Polytechnic Institute", Kyiv, Ukraine \\ gan@geobud.kiev.ua \\ ORCID: http://orcid.org/0000-0003-0832-1338
}

ARTICLE INFO

Article history:

Received date 11.09.2020

Accepted date 14.10.2020

Published date 30.10 .2020

Section:

Building

DOI

$10.21303 / 2313-8416.2020 .001430$

KEYWORDS

subsidence soils

explosive impulse

explosives

soil compaction

explosive impulse duration

explosive density

ultrasonic radiation

soil deformation

\section{ABSTRACT}

Significant growth rates of construction require large areas prepared in advance. Given the complexity and large scale of construction on subsidence soils, an important issue remains their compaction. On the article, on the parameters of the explosion momentum of TNT-free explosive compositions based on ammonium nitrate (AN) and after ultrasonic treatment of ammonium nitrate were analytically investigated, and their comparison with ammonite №6 and igdanite was also compared. The principles of explosive pulse control by regulating the content and density of explosives due to ultrasonic radiation and foaming of low-density explosive mixtures have been developed and substantiated. Set the minimum value of the peak pressure at the interface "detonation product - environment" from time for foamed explosives after treatment with ultrasonic radiation. The object of research: Reclamation works and construction. Management of compaction of subsidence and flooded soils by directed action of explosive systems.

Investigated problem: Taking into account that the method of compaction of subsiding loess soils with the energy of explosion is used in built-up areas, of particular importance is the control of the explosive pulse through the regulation of the content and density of explosives by ultrasonic radiation and foaming of low-density explosive mixtures this is done to ensure the required degree of compaction of the subsidence of the soil mass and to reduce the harmful seismic impact on the surrounding structures.

The main scientific results: The dependence of the duration of the explosive pulse growth on the charge radius for different types of low-density explosives has been established, which indicates that the longest growth time of the explosive pulse is observed for charges based on foamed explosives, both conventional and ultrasonic treated. The dependences of the degree of soil compaction during the explosion of overhead charges of different types of explosives in the polymer housing on the specific costs of explosives are obtained. The research results allow to develop technological methods of controlling the parameters of the explosive pulse by using explosive density, which provides the opportunity to increase the efficiency of explosive energy to maintain the required degree of compaction of subsidence loess soils to a certain depth while seismic protection.

The area of practical use of the research results: the use of this type of compaction of unstable soil is possible in the construction industry, in the mining industry and in the military.

Innovative technological product: the methods of compaction of unstable soil with the energy of the explosion work when changing the parameters of the pulse, which will minimize the loss of energy in the blasting zone and increase the range of a single charge.

Scope of the innovative technological product: the application of this method is possible: for compaction of unstable soil before construction, for soil compaction of runways at field airfields, for demining.

(C) The Author(s) 2020. This is an open access article under the CC BY license http://creativecommons.org/licenses/by/4.0).

\section{Introduction}

\section{1. The problem}

Management of compaction of subsidence soils and water-saturated soil, by the directed action of explosive systems is of great importance in geotechnology in reclamation works and in 
construction. The traditional problem of such systems is to change the parameters of the pulse, which will minimize energy losses in the blasting zone and increase the range of one charge.

Taking into account that the method of compaction of subsiding loess soils with the energy of explosion is used in built-up areas, of particular importance is the control of the explosive pulse through the regulation of the content and density of explosives by ultrasonic radiation and foaming of low-density explosive mixtures this is done to ensure the required degree of compaction of the subsidence of the soil mass and to reduce the harmful seismic impact on the surrounding structures.

\subsection{Analysis of recent research and publications}

In the last decades of the last century, the Institute of Hydromechanics of the National Academy of Sciences of Ukraine performed a significant amount of research on the parameters of mass explosions, improved recipes for TNT-free explosive compositions based on ammonium nitrate depending on the tasks, soil characteristics and mining and geological conditions of drilling and blasting. Today, the improvement of explosive foam systems continues by treating them with ultrasonic radiation [1, 2], developing designs of horizontal cylindrical charges for compaction of subsidence soils, and delivery to the site of blasting.

Providing the necessary parameters of the explosive pulse of explosives for compaction of subsidence soils is an urgent task, because reducing the volumetric concentration of charge energy in contact with the environment by reducing the explosive density reduces the peak detonation pressure while extending the duration of the explosive pulse. This allows to increase the efficiency of the energy of the explosive transformation in the near range of the explosion [3].

\section{3. Proposed solution to the problem}

The aim of research is to further expand the scope of TNT-free explosive based on ammonium nitrate by selecting the composition, changing the density of explosive systems, as well as improving methods of explosive pulse control and scientific and practical justification of its parameters for compaction of subsidence soils. It is necessary to conduct an analytical assessment of the capabilities of the developed methods of controlling the parameters of the explosive momentum of low-density explosive mixtures for further regulation of the impact on subsidence of the soil environment and development of technological schemes for compaction of subsidence soils.

\section{Materials and methods}

\section{1. Device for the preparation of developed water-filled foam}

At present, there are no special machines for compaction of areas of subsidence unstable soils due to the use of explosion energy. However, a special device has been developed [4] for the preparation of water-filled foam explosive composite. The device allows to carry out consolidation of territories of subsidence soils by shuttle movement of a foam trunk along the work front with a coating of a layer of soil foam substance or recesses in it with the possible use of a soft shell and subsequent detonation of the explosive composite thread detonating cord.

\section{2. Limitation of blasting action and seismic action of explosive charges}

When studying the parameters of the explosive impulse to compact the areas of subsidence soils due to surface or horizontal cylindrical charges of explosives requires limiting the brisant action of the explosive charges and seismic action of explosive charges. This can be achieved through the use of low-density explosive mixtures, foamed explosive compositions, treatment with ultrasonic radiation. Analysis of previous studies in solving the problem of finding the radius of the soil compaction zone around the well [1-6] low-density foamed compositions showed that it is necessary to determine the pressure at their contact "detonation products - environment". The radius of the seismic zone is calculated using Newton's law of dynamic similarity and is used to ensure the condition of seismic resistance of protected objects. Based on numerous experimental data, researchers believe that the effectiveness of compaction of subsidence soils when using an explosion is determined not only by the maximum pressure at the front of the detonation wave, but also the duration of the explosive pulse. This is manifested in the increase of the general forms of operation of the explosion at large distances from the explosive charge, and, accordingly, in the improvement of the compaction of the soil mass at a considerable distance. 
In this regard, it is necessary to investigate the relationship between the effectiveness of explosives (igdanite, ammonite No. 6) and foamed explosive composition, both conventional and after ultrasonic treatment (surfactants with ultrasound) for compaction of sedimentary water-saturated soils with maximum pressure, duration and the form of the explosive impulse that occurs at the boundary "detonation products - environment".

When calculating the explosive momentum of standard explosives (igdanite, ammonite No. 6) and foamed explosive compositions with and without ultrasonic treatment, the method developed by N. Kozakov was used [7].

When the detonation wave reaches the boundary of the section "detonation products - environment" there is a shock wave, the initial pressure of which is determined by the solution of the system of equations:

$$
\begin{gathered}
U_{H}=\sqrt{\left(P_{\max }-P_{0}\right) \cdot\left(v_{0}-v\right)} \\
P_{\max }=B\left[\left(\frac{\rho}{\rho_{0}}\right)^{n}-1\right], \\
U_{H}=\frac{D}{K+1}\left(1-\sqrt{2 K} \frac{\frac{P_{\max }}{2 P_{c p}}-1}{\sqrt{(K-1) \frac{P_{\max }}{2 P_{c p}}+(K-1)}}\right) \Rightarrow P_{\max } \succ P_{c p}, \\
U_{H}=\frac{D}{K+1}\left\{1+\frac{2 K}{K-1}\left[1-\left(\frac{P_{\max }}{2 P_{c p}}\right)^{\frac{K-1}{2 K}}\right]\right\} \Rightarrow P_{\max } \prec 2 P_{c p},
\end{gathered}
$$

where $P_{\max }$ - initial pressure at the shock wave front; $v_{0}=\frac{1}{\rho_{0}}-$ specific volume of undisturbed environment; $v=\frac{1}{\rho}$ - the specific volume of the medium at the front of the shock wave; $D$ - detonation velocity; $P_{c p}$ - pressure in the well under the condition of instantaneous detonation.

$$
P_{c p}=(k-1) \rho_{0}^{\prime} Q_{v}
$$

where $Q_{v}=427 \cdot Q \cdot g$ - explosion heat per unit mass of explosives; $Q$ - explosion heat; $g=9.81 \mathrm{~N} / \mathrm{m}^{2}-$ acceleration of gravity; $k=3$ - isoentropy index in the overcompacted state of detonation products.

$$
B=\frac{\rho c^{2}}{n}
$$

where $\rho$ - environment density; $c$ - speed of the blast shock wave.

In the conditions of real detonation, the pressure at the interface "detonation products - environment" is described by the following dependences.

$$
\begin{gathered}
P_{r}=\left(\frac{r_{0}}{r}\right)^{6}\left[\left(P_{\max } \frac{r^{\prime \prime \prime}-r}{r^{\prime \prime}-r_{0}}\right)+P_{\min }\left(1-\frac{r^{\prime \prime \prime}-r}{r^{\prime \prime}-r_{0}}\right)\right] \text { proved } r_{0} \prec r \prec r^{\prime \prime \prime}, \\
P_{r}=\left(\frac{r_{0}}{r}\right)^{6}\left[\left(P_{\min } \frac{r^{\prime \prime}-r}{r^{\prime \prime}-r^{\prime \prime \prime}}\right)+P_{c p}\left(1-\frac{r^{\prime \prime}-r}{r^{\prime \prime}-r^{\prime \prime \prime}}\right)\right] \text { proved } r^{\prime \prime \prime} \prec r \prec r^{\prime \prime}, \\
P_{r}=P_{c p}\left(\frac{r_{0}}{r}\right)^{6} \text { proved } r^{\prime \prime} \prec r \prec r^{\prime},
\end{gathered}
$$




$$
P_{r}=P_{r}^{\prime}\left(\frac{r^{\prime}}{r}\right)^{2 \gamma} \text { proved } r \prec r^{\prime},
$$

where $r$ " - the position of the distribution limit at which the pressure due to equalization reaches a minimum; $r_{0}$ - explosive charge radius; $r$ - radius of the distribution boundary "detonation products - environment"; $\gamma$-indicator of the isoentropy of an ideal gas, which is $\gamma=1.3$.

Unknown indicators $\mathrm{P}, r$ " and $r$ "' are determined from the ratios:

$$
\begin{aligned}
& P_{\min }=1.4 P_{c p}-0.4 P_{\max }, \\
& r^{\prime \prime \prime}=r_{0}\left(1-K_{1} \frac{U_{H}}{D}\right), \\
& r^{\prime \prime}=r_{0}\left(1+K_{2} \frac{U_{H}}{D}\right),
\end{aligned}
$$

where $K_{1}=0.6 ; K_{2}=1.7 \div 2.5$ - dimensionless coefficients.

The path from $r_{0}$ to $r$ "' the distribution limit will pass in time:

$$
t_{1}=0.64 \frac{r_{0}}{D}
$$

and the path $r$ '"'-r"'- the distribution limit will pass in time:

$$
t_{2}=\frac{1.2 r_{0}+2 r^{\prime \prime}}{D} .
$$

The pressure $P_{r}$ will be: at the time $t_{1}$ :

$$
P_{r}=P_{\min }\left(\frac{r_{0}}{r^{\prime \prime \prime}}\right)^{6}
$$

at the time $t_{2}$ :

$$
P_{r}=P_{c p}\left(\frac{r_{0}}{r^{\prime \prime}}\right)^{6}
$$

and at the time $t=0$ :

$$
P_{r}=P_{\max } .
$$

The graph of dependence $P_{r}$ on $t$ is approximated by dependence:

$$
P=P_{0} e^{-\alpha t},
$$

where $\alpha$-logarithmic decrement of attenuation, which depends on the properties of the environment. The coefficients $P_{0}$ and $\alpha$ are from the equations:

- when $t=0$

$$
P=P_{0}=P_{\max } ;
$$

- when $t=t_{1}$

$$
P_{r}^{\prime}=P_{\min }\left(\frac{r_{0}}{r^{\prime \prime \prime}}\right)^{6}
$$


Let's obtain:

$$
\alpha=\frac{l_{n} P_{\max }-l_{n} P_{r}^{\prime}}{t_{1}} .
$$

The time of increase of the explosive pulse is determined by the formula:

$$
\tau=\frac{0.4 r_{0}}{3 / 4 D} .
$$

Using the basic relations given above, the calculation of the parameters of the explosive pulse for different explosives from the explosion of charges with a radius of $30 \mathrm{~mm}$ in the sand. The main source data are given in Table 1.

Table 1

\begin{tabular}{|c|c|c|c|c|}
\hline \multirow[b]{2}{*}{ Name } & \multicolumn{4}{|c|}{ Explosives } \\
\hline & Ammonite No. 6 & Igdanite & $\begin{array}{c}\text { Foamed } \\
\text { explosive }\end{array}$ & $\begin{array}{l}\text { Foamed explosive } \\
\text { substance that is } \\
\text { treated with ultrasound }\end{array}$ \\
\hline Explosive density, $\rho_{0} \mathrm{~g} / \mathrm{cm}^{3}$ & 0.8 & 0.8 & 0.6 & 0.5 \\
\hline Detonation speed $D, \mathrm{~m} / \mathrm{sec}$. & 3700 & 3450 & 1500 & 1500 \\
\hline Explosion heat $Q, \mathrm{kcal} / \mathrm{kg}$ & 1030 & 870 & 850 & 840 \\
\hline Environmental density $\rho, \mathrm{kg} / \mathrm{m}^{3}$ & 2800 & 2800 & 2800 & 2800 \\
\hline Propagation speed of the shock wave, $\mathrm{c} \mathrm{m} / \mathrm{sec}$. & 4950 & 4950 & 4950 & 4950 \\
\hline Explosive charge radius, $r_{0}, \mathrm{~m}$ & $0.03-0.09$ & $0.03-0.09$ & $0.03-0.09$ & $0.03-0.09$ \\
\hline
\end{tabular}

Physical and dynamic characteristics of explosives

According to the calculations of Table $\mathbf{2}$ in Fig. 1 graphically show the explosive impulses for ammonite No. 6, igdanite and foamed explosives when detonating explosive charges with a radius of $30 \mathrm{~mm}$ in subsidence loess soils. In Fig. 2 shows the time of growth of the explosive momentum of the explosives.

Table 2

\begin{tabular}{|c|c|c|c|c|}
\hline \multirow[b]{2}{*}{ Name } & \multicolumn{4}{|c|}{ Explosives } \\
\hline & $\begin{array}{l}\text { Ammonite } \\
\text { No. } 6\end{array}$ & Igdanite & $\begin{array}{l}\text { Foamed } \\
\text { explosive }\end{array}$ & $\begin{array}{l}\text { Foamed explosive substance } \\
\text { that is treated with ultrasound }\end{array}$ \\
\hline Initial pressure at the front of the wave, $P_{\max } \cdot 10^{9} \mathrm{~N} / \mathrm{m}^{2}$ & 8.19 & 6.92 & 5.52 & 4.18 \\
\hline $\begin{array}{l}\text { Pressure in the well, under the condition of } \\
\text { instantaneous detonation, } P_{\text {ave }} \cdot 10^{9} \mathrm{~N} / \mathrm{m}^{2}\end{array}$ & 6.89 & 5.82 & 4.27 & 3.25 \\
\hline Minimum pressure, $P_{\min } \cdot 10^{9} \mathrm{~N} / \mathrm{m}^{2}$ & 6.37 & 5.38 & 3.77 & 3.26 \\
\hline Pressure at time $t_{1}, P_{r} \cdot 10^{9} \mathrm{~N} / \mathrm{m}^{2}$ & 1.9 & 1.76 & 0.31 & 0.4 \\
\hline Pressure at time $t_{2}, P_{r} \cdot 10^{9} \mathrm{~N} / \mathrm{m}^{2}$ & 0.22 & 0.24 & 0.009 & 0.016 \\
\hline Passage time of the section from $r^{0}$ to $r^{\prime \prime}, t_{1}, \times 10^{-6} \mathrm{sec}$ & 5.1 & 5.57 & 12.8 & 12.8 \\
\hline Passage time of the section from $r$ "' to $r$ "', $t_{2}, \times 10^{-6} \mathrm{sec}$. & 38.5 & 39.94 & 135.4 & 122.3 \\
\hline \multirow{3}{*}{$\begin{array}{l}\text { Growth time of the explosive } \\
\text { pulse, microsec. when: }\end{array}$} & 4.3 & 4.6 & 10.6 & 10.6 \\
\hline & 8.65 & 9.28 & 21.33 & 21.33 \\
\hline & 12.97 & 13.91 & 32.0 & 32.0 \\
\hline
\end{tabular}

Estimated parameters of the explosive pulse of explosives 


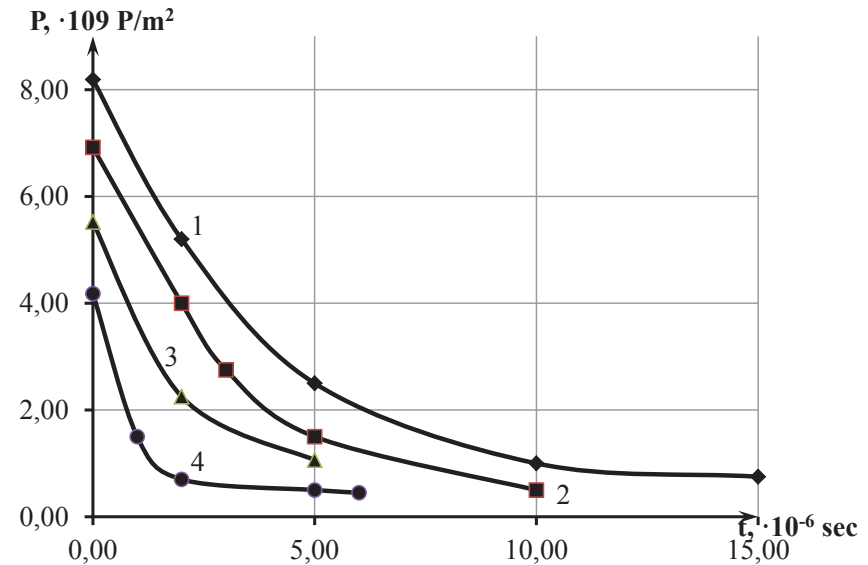

Fig. 1. The development of explosion pressure at the interface

"detonation products - environment" in time: 1 - Ammonite No. 6; 2 - Igdanit;

3 - Foamed explosive; 4 - Foamed explosive substance that is treated with ultrasound

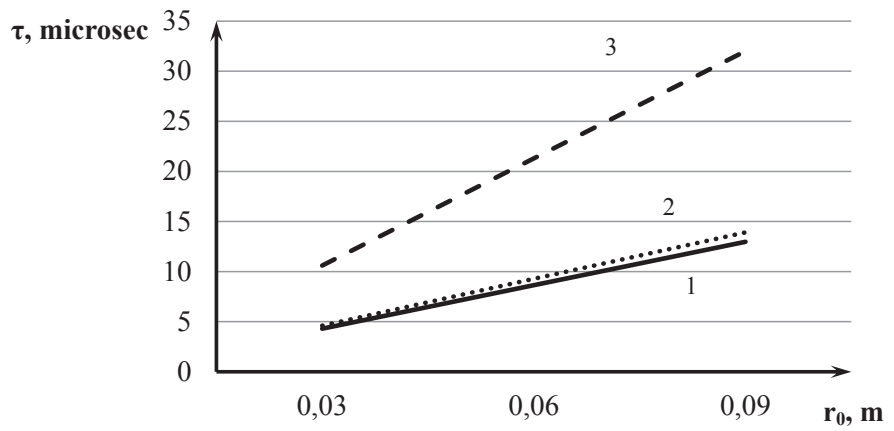

Fig. 2. The dependence of the duration of the growth of the explosive pulse on the charge radius of the explosive: 1 - Ammonite No. 6; 2 - Igdanit; 3 - Foamed explosive and foamed explosive substance that is treated with ultrasound

As can be seen from Fig. 1, in charges based on foamed explosives, the main part of the explosive pulse has a minimum peak pressure value and a maximum duration, both for explosives with the lowest detonation rate and the largest width of the chemical reaction zone. The pressure of the foamed explosive after treatment with ultrasonic radiation is slightly lower than that of conventional foamed explosive, but the duration of the explosive pulse is shorter.

Analysis of theoretical studies shows that the maximum pressure of foamed explosives treated with ultrasound is $4.18 \cdot 10^{-9} \mathrm{~N} / \mathrm{m}^{2}$, which is $49 \%$ less compared to ammonite No. 6 and $40 \%$ less compared to Igdanite. For ordinary foamed explosives, the maximum pressure is $5.52 \cdot 10^{-9} \mathrm{~N} / \mathrm{m}^{2}$, which is $33 \%$ less compared to ammonite No. 6 and $20 \%$ compared to Igdanite. The maximum duration of the explosive pulse at the boundary "detonation products - environment" for foamed explosives treated with ultrasonic radiation is $122.3 \cdot 10^{-6} \mathrm{sec}$, that is 3.2 times longer than ammonite No. 6 and 3 times longer for Igdanite. For foamed explosives, the maximum duration of the explosive pulse is $135.4 \cdot 10^{-6}$ sec., which is 3.5 times longer than ammonite No. 6 and 3.37 times longer than Igdanite.

A similar regularity is observed in the study of the growth duration of the explosive pulse, which for foamed explosives, both conventional and after treatment with ultrasonic radiation, is in the range from 10.6 microsec. to 32 microsec. For ammonite №6 the parameter is set from 4.3 microsec. to 12.97 microsec., for Igdanite the parameter is set - from 4.6 microsec. to 13.91 microsec.

Thus, the data of theoretical calculations indicate that the greatest effect in the compaction of subsidence soils can be achieved through the use of foamed explosives, both conventional and sonicated, which at a minimum pressure at the boundary "detonation product - environment" have a significant duration of explosive impulse, which in turn should contribute to the uniform compaction of subsidence soils to the required thickness. 


\section{Results and experimental confirmation}

To confirm the theoretical calculations in the field, studies were conducted to determine the operation of overhead charges of explosives (Fig. 3) of different power (thickness) using different types of explosives (igdanite and low-density foam mixture with aluminum powder - AN/SF/AP) on its ability to provide compaction of loess soils.

When studying in vivo a low-density foamed explosive mixture AN/SF/AP, a standard explosive AN/DF was used for comparison. Overhead charges were located in pre-designed and moistened trenches over the entire area of the seal and their counter-initiation (Fig. 3). The mass of the explosive charge was chosen depending on the thickness of the subsidence of the soil and was $10-15 \mathrm{~kg} / \mathrm{m}$ of foam mixture.

Table 3

The results of compaction of loess soils by blasting when using overhead charges of different power

\begin{tabular}{|c|c|c|c|c|c|c|c|c|}
\hline \multirow{3}{*}{ No. } & \multirow{3}{*}{ 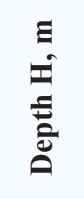 } & \multirow{3}{*}{$\begin{array}{l}\text { Initial soil density, } \\
\qquad 10^{3} \mathrm{~kg} / \mathrm{m}^{3}\end{array}$} & \multicolumn{6}{|c|}{ Density of the condensed soil at various thickness of overhead charges, $10^{3} \mathrm{~kg} / \mathrm{m}^{3}$} \\
\hline & & & \multicolumn{3}{|c|}{ Igdanite AN/DF } & \multicolumn{3}{|c|}{$\begin{array}{c}\text { Low-density foamed explosive mixture } \\
\text { AN/SF/AP }\end{array}$} \\
\hline & & & $50 \mathrm{~mm}$ & $75 \mathrm{~mm}$ & $100 \mathrm{~mm}$ & $50 \mathrm{~mm}$ & $75 \mathrm{~mm}$ & $100 \mathrm{~mm}$ \\
\hline 1 & 0.25 & $1.35-1.37$ & 1.63 & 1.66 & 1.68 & 1.70 & 1.72 & 1.75 \\
\hline 2 & 0.50 & $1.36-1.38$ & 1.62 & 1.64 & 1.65 & 1.67 & 1.69 & 1.71 \\
\hline 3 & 0.75 & $1.34-1.36$ & 1.58 & 1.60 & 1.62 & 1.63 & 1.65 & 1.68 \\
\hline 4 & 1.00 & $1.40-1.42$ & 1.60 & 1.63 & 1.65 & 1.60 & 1.61 & 1.66 \\
\hline 5 & 1.25 & $1.30-1.32$ & 1.42 & 1.53 & 1.57 & 1.57 & 1.58 & 1.60 \\
\hline 6 & 1.50 & $1.41-1.43$ & no change & 1.51 & 1.63 & 1.51 & 1.63 & 1.64 \\
\hline 7 & 2.00 & $1.50-1.52$ & no change & no change & 1.61 & no change & 1.58 & 1.61 \\
\hline 8 & 2.50 & $1.35-1.37$ & no change & no change & no change & no change & no change & 1.50 \\
\hline 9 & 3.00 & $1.44-1.46$ & no change & no change & no change & no change & no change & 1.49 \\
\hline
\end{tabular}

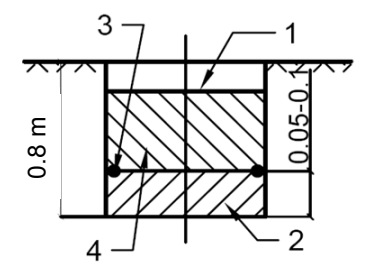

Fig. 3. Soil compaction by overhead explosive charges: 1 - trench; 2 - charge of explosive foam;

3 - detonation cord; 4 - soil compaction

Fig. 4-7 show the data of effective compaction of loess soils as described above with different power (thickness) of the overhead charge using different types of explosives (Igdanite AN/DF and low-density foamed explosive mixture AN/SF/AP).

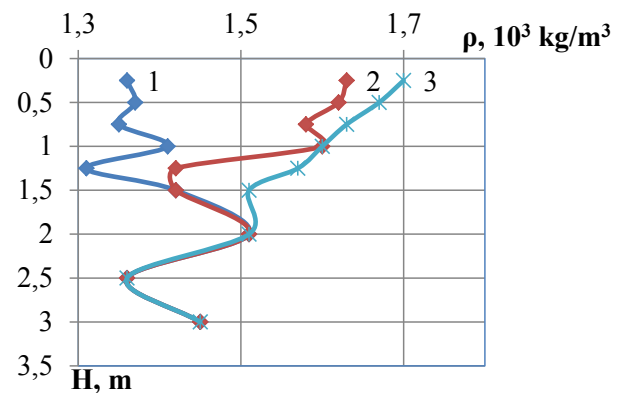

Fig. 4. Dependence of soil mass compaction on the type of explosive with a thickness of $50 \mathrm{~mm}$ : 1 - initial density of loess soil; 2 - Igdanite (AN/DF); 3 - low-density foamed explosive mixture (AN/SF/AP) 


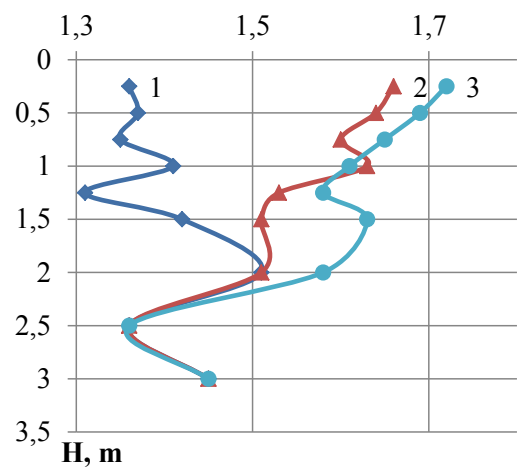

$\rho, 10^{3} \mathrm{~kg} / \mathrm{m}^{3}$

Fig. 5. Dependence of soil mass compaction on the type of explosive with a thickness of $75 \mathrm{~mm}$ : 1 - initial density of loess soil; 2 - Igdanite (AN/DF); 3 - low-density foamed explosive mixture (AN/SF/AP)

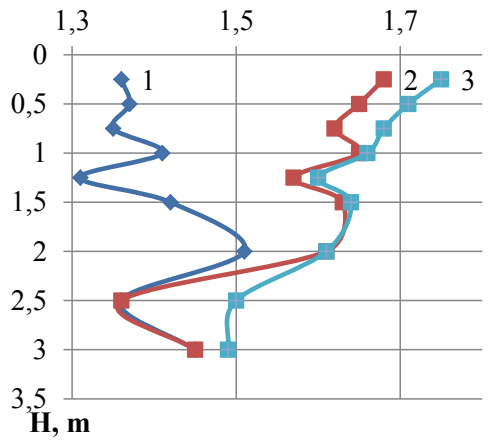

$\rho, 10^{3} \mathrm{~kg} / \mathrm{m}^{3}$

Fig. 6. Dependence of soil mass compaction on the type of explosive with a thickness of $100 \mathrm{~mm}$ : 1 - initial density of loess soil; 2 - Igdanite (AN/DF); 3 - low-density foamed explosive mixture (AN/SF/AP)

The dependence of the depth of compaction of the soil mass on the power of the explosive charge (Fig. 7) is linear. At charge capacities of 50, 75, and $100 \mathrm{~mm}$, the depth of soil compaction with low-density explosives, respectively, on 25,20 and $17 \%$ more than igdanite.

As can be seen from Table 3 and from Fig. 4-7, the character of compaction of the soil mass by surface overhead charges has a nonlinear pulsating character, which attenuates with depth. This behavior of the soil mass during compaction is explained by the specifics of the development of the deformation process. At the initial stage of expansion of explosive gases, a compacted zone is formed with the maximum value of deformation at the contact with the gas cavity and its gradual uniform degeneration in the direction of the boundary with the undeformed array. In the next stage, after the pressure drop of the explosive gases due to the unloading of the compressed massif, the soil moves back to the cavity. At the same time characteristic zones of unloading, i. e. partial decrease in density are formed.

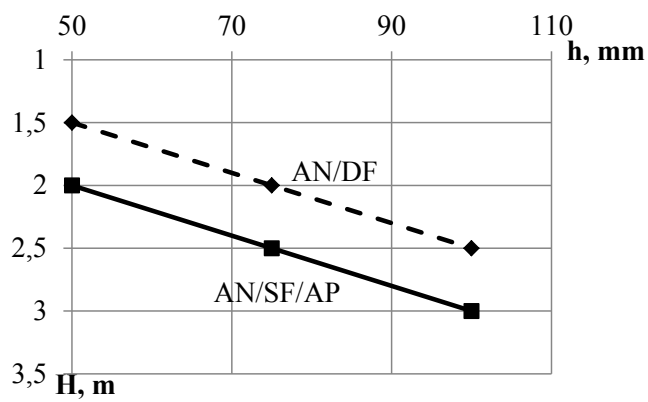

Fig. 7. The dependence of the depth of compaction of the soil mass on the power of the explosive charge 
The nature of the amplitude of the density pulsation depends on the parameters of the pulse of the explosive. The lower the initial pressure at the front of the detonation wave and the longer its growth in the explosive pulse, the greater the amplitude of the pulsation. This in turn leads to a longer action of explosive gases on the surrounding array with a corresponding increase in density.

Compaction of the soil mass is performed at a depth of $1.25 \mathrm{~m}, 1.5 \mathrm{~m}$ and $2.0 \mathrm{~m}$ at an explosive power of $50 \mathrm{~mm}, 75 \mathrm{~mm}$, and $100 \mathrm{~mm}$, respectively, for igdanite and a depth of $1.5 \mathrm{~m}$, $2.0 \mathrm{~m}$ and $3.0 \mathrm{~m}$ at an explosive charge capacity of $50 \mathrm{~mm}, 75 \mathrm{~mm}$, and $100 \mathrm{~mm}$ for low-density explosives, respectively. The initial compaction at a depth of $0.25 \mathrm{~m}$ of low-density explosive is slightly higher than when using igdanite, and is in the range for low-density explosive from 1.7 to $1.75 \cdot 10^{3} \mathrm{~kg} / \mathrm{m}^{3}$ and for Igdanite - from 1.63 to $1.68 \cdot 10^{3} \mathrm{~kg} / \mathrm{m}^{3}$. Thus, it is possible to choose the power of the explosive charge, which will ensure the compaction of the soil mass to the required depth.

\section{Discussion}

The technology of compacting structurally unstable soils using explosion energy was first applied in the 30s of the 20th century. Since then, the technology of work and the compositions of explosives that are used have been significantly improved [8-10]. But the problem of the safety of conducting explosions near buildings remains. It is possible to regulate the impact of blasting by controlling the explosive parameters of explosives. Thus, to control the seismic impact on buildings and structures.

The results of the experiments indicate that low-speed and low-density explosives provide compaction of subsidence loess soils to a greater depth of the soil mass. At the same time, low-density foamed charges based on AN/SF/AP provide compaction to a depth of 2730 explosive power in comparison with Igdanite, which provides compaction to a depth of 20-25 explosive power.

This can be explained by the redistribution of energy in the explosive pulse by reducing the peak pressure and increasing the total duration of the compression phase. This reduces energy losses in the near area of the explosion due to overconsolidation compaction of the soil and increases the duration of the compaction itself, which directly affects its depth.

The obtained data are confirmed by field research, and indicate that it is possible to reduce energy consumption in the near explosion zone and provide the required duration of the compression phase, resulting in the required degree of compaction of the subsidence soil mass.

Despite the high technological indicators of soil compaction, blasting operations are accompanied by special requirements for the transportation, storage and use of explosives, as well as ensuring seismic safety for surrounding buildings and structures.

The prospects for this study are very broad, they encompass further research into the characteristics of foamed explosive compositions. It is also necessary to develop a device and method for the preparation of a foamed explosive directly at the site of blasting operations. Thus, the safety of blasting operations will be ensured and the need for the cost of transporting and storing explosives will disappear.

\section{Conclusions}

The dependence of the maximum pressure at the detonation wave front for different types of explosives on the duration of the explosive pulse is obtained. The maximum pressure of these explosives is lower by $20-49 \%$, and the duration of the explosive pulse is 3-3.5 times longer than a standard low-density explosive.

Research results have shown that the use of the explosion energy of overhead charges allows to completely or partially eliminate the subsidence properties of loess soils to the entire depth of subsidence of the stratum. The application of external load to the soil mass creates a three-dimensional deformation of the environment and soil compaction, mainly due to the reduction of pore space with elastic deformation of grains, their mutual movement, deformation and destruction of ligaments.

Compaction of sedimentary soils with the top charges allows to reach compression of soil on 20-30 capacities of a charge of explosive. 


\section{References}

[1] Han, A. L., Vapnichna, V. V., Vasilchuk, O. S. (2018). Study of ultrasonic exposure effect on retaining ability of diesel fuel in ammonium nitrate. The Journal of Zhytomyr State Technological University. Series: Engineering, 1 (81), 217-222. doi: http:// doi.org/10.26642/tn-2018-1(81)-217-222

[2] Han, O. V., Boyko, V. V., Han, A. L., Kravets, V. G., Vapnichna, V. V. (2019). Changes in the porosity and retention capacity of ammonium nitrate under the influence of ultrasonic irradiation. Problems of Geoengineering and Underground Urbanism. Kyiv. Available at: https://geobud.kpi.ua/conference/problemygeoinzhenerii2/772

[3] Sadovskii, M. A. (1971). Mekhanicheskii effekt podzemnogo vzryva. Moscow: Nedra, 221.

[4] Zolotukhin, K. S., Han, O. V., Boiko, V. V., Prykhodko, Yu. P., Orlov, Yu. Iu., Pluzhnyk, V. I., Honchar, V. K. (2018). Pat. No. 122425 UA. Prystrii dlia pryhotuvannia vodonapovnenoi vspinenoi vybukhovoi kompozytsii. na korysnu model. MPK E21C 37/00. No. u 2017 06787; declareted: 30.06.2017; published: 10.01.2018, Bul. No. 1. Available at: http://uapatents. com/4-122425-pristrijj-dlya-prigotuvannya-vodonapovneno-vspineno-vibukhovo-kompozici.html

[5] Bojko, V.V., Han, A.L., Han. O.V. (2018). Surfacing sunflowers by improved charges of small density. Zbirnyk naukovyh prats Nationalnogo girnichogo universytetu, 55, 152-161. Available at: http://znp.nmu.org.ua/pdf/2018/55/17.pdf

[6] Litvin, L. N. (1981). Novye metody razrusheniia i mekhanika gornykh porod. Kyiv: Naukova dumka, 136-140.

[7] Kazakov, H. H. (1966). Razrushenie gornoi porody udarnym deistviem vzryva. Moscow: IGD im. A. A.Skochinskogo.

[8] Minaev, O. P. (2018). Effective Blasting Method of Compacting Sand Foundation Beds for Various Structures. Power Technology and Engineering, 51 (5), 507-512. doi: http://doi.org/10.1007/s10749-018-0864-x

[9] Shakeran, M., Eslami, A., Ahmadpour, M. (2016). Geotechnical Aspects of Explosive Compaction. Shock and Vibration, 2016, 1-14. doi: http://doi.org/10.1155/2016/6719271

[10] Vovk, A. A., Kravets, V. H., Demeshchuk, L. Y. et. al. (1976). Sposob uplotneniya prosadochnyh lessovyh hruntov. A. S. 572094 (SSSR). SKTB Instituta heofiziki AN USSR. MKY E02D 3/10, UDK 624.5. 